\title{
Some results on fixed points of $\alpha-\psi$-Ciric generalized multifunctions
}

\author{
B Mohammadi', S Rezapour ${ }^{2}$ and N Shahzad ${ }^{3 *}$
}

${ }^{\text {"Correspondence: }}$

nshahzad@kau.edu.sa

${ }^{3}$ Department of Mathematics, King Abdulaziz University, P.O. Box 80203,

Jeddah, 21859, Saudi Arabia

Full list of author information is

available at the end of the article

\begin{abstract}
In 2012, Samet, Vetro and Vetro introduced $\alpha$ - $\psi$-contractive mappings and gave some results on a fixed point of the mappings (Samet et al. in Nonlinear Anal. 75:2154-2165, 2012). In fact, their technique generalized some ordered fixed point results (see (Alikhani et al. in Filomat, 2012, to appear) and (Samet et al. in Nonlinear Anal. 75:2154-2165, 2012)). By using the main idea of (Samet et al. in Nonlinear Anal. 75:2154-2165, 2012), we give some new results for $\alpha$ - $\psi$-Ciric generalized multifunctions and some related self-maps. Also, we give an affirmative answer to a recent open problem which was raised by Haghi, Rezapour and Shahzad in 2012.
\end{abstract}

Keywords: $\alpha$ - $\psi$-Ciric generalized multifunction; fixed point; quasi-contractive multifunction

\section{Introduction}

In 2012, Samet, Vetro and Vetro introduced $\alpha-\psi$-contractive mappings and gave fixed point results for such mappings [1]. Their results generalized some ordered fixed point results (see [1]). Immediately, using their idea, some authors presented fixed point results in the field (see, for example, [2]). Denote by $\Psi$ the family of nondecreasing functions $\psi:[0,+\infty) \rightarrow[0,+\infty)$ such that $\sum_{n=1}^{+\infty} \psi^{n}(t)<+\infty$ for each $t>0$. It is well known that $\psi(t)<t$ for all $t>0$. Let $(X, d)$ be a metric space, $\beta: 2^{X} \times 2^{X} \rightarrow[0,+\infty)$ be a mapping and $\psi \in \Psi$. A multivalued operator $T: X \rightarrow 2^{X}$ is said to be $\beta$ - $\psi$-contractive whenever $\beta(T x, T y) H(T x, T y) \leq \psi(d(x, y))$ for all $x, y \in X$, where $H$ is the Hausdorff distance (see [2]). Alikhani, Rezapour and Shahzad proved fixed point results for $\beta$ - $\psi$-contractive multifunctions [2]. Let $(X, d)$ be a metric space, $\alpha: X \times X \rightarrow[0,+\infty)$ be a mapping and $\psi \in \Psi$. We say that $T: X \rightarrow 2^{X}$ is an $\alpha-\psi$-Ciric generalized multifunction if

$$
\alpha(x, y) H(T x, T y) \leq \psi\left(\max \left\{d(x, y), d(x, T x), d(y, T y), \frac{d(x, T y)+d(y, T x)}{2}\right\}\right)
$$

for all $x, y \in X$. One can find an idea of this notion in [3]. Also, we say that the self-map $F$ on $X$ is $\alpha$-admissible whenever $\alpha(x, y) \geq 1$ implies $\alpha(F x, F y) \geq 1$ [1]. In this paper, we give fixed point results for $\alpha-\psi$-Ciric generalized multifunctions.

In 2012, Haghi, Rezapour and Shahzad proved that some fixed point generalizations are not real ones [4]. Here, by presenting a result and an example, we are going to show that obtained results in this new field are real generalizations in respect to old similar results in the literature (compare the next result and the example with main results of [5] and [6]). The following result has been proved in [7].

C) 2013 Mohammadi et al.; licensee Springer. This is an Open Access article distributed under the terms of the Creative Commons Attribution License (http://creativecommons.org/licenses/by/2.0), which permits unrestricted use, distribution, and reproduction in any medium, provided the original work is properly cited. 
Lemma 1.1 Let $(X, d)$ be a complete metric space, $\alpha: X \times X \rightarrow[0, \infty)$ be a function, $\psi \in \Psi$ and $T$ be a self-map on $X$ such that

$$
\alpha(x, y) d(T x, T y) \leq \psi\left(\max \left\{d(x, y), d(x, T x), d(y, T y), \frac{1}{2}[d(x, T y)+d(y, T x)]\right\}\right)
$$

for all $x, y \in X$. Suppose that $T$ is $\alpha$-admissible and there exists $x_{0} \in X$ such that $\alpha\left(x_{0}\right.$, $\left.T x_{0}\right) \geq 1$. Assume that if $\left\{x_{n}\right\}$ is a sequence in $X$ such that $\alpha\left(x_{n}, x_{n+1}\right) \geq 1$ for all $n$ and $x_{n} \rightarrow x$, then $\alpha\left(x_{n}, x\right) \geq 1$ for all $n$. Then $T$ has a fixed point.

Here, we give the following example which shows that Lemma 1.1 holds while we cannot use some similar old results, for example, Theorem 1 of [5].

Example 1.1 Let $M_{1}=\left\{\frac{m}{n}: m=0,1,3,9, \ldots\right.$ and $\left.n=3 k+1(k \geq 0)\right\}, d(x, y)=|x-y|, M_{2}=$ $\left\{\frac{m}{n}: m=1,3,9,27, \ldots\right.$ and $\left.n=3 k+2(k \geq 0)\right\}$ and $M_{3}=\{2 k: k \geq 1\}$. Now, put $M=M_{1} \cup$ $M_{2} \cup M_{3}$ and define the self-map $T: M \rightarrow M$ by $T x=\frac{3 x}{11}$ whenever $x \in M_{1}, T x=\frac{x}{8}$ whenever $x \in M_{2}$ and $T x=2 x$ whenever $x \in M_{3}$. Put $M(x, y)=\max \{d(x, y), d(x, T x), d(y, T y)$, $\left.\frac{d(x, T y)+d(y, T x)}{2}\right\}$ for all $x, y \in M$. If $x \in M_{1}$ and $y \in M_{2}$, then $d(T x, T y)=\left|\frac{3 x}{11}-\frac{y}{8}\right|=\frac{3}{11}\left|x-\frac{11 y}{24}\right|$. Now, we consider two cases. If $x>\frac{11}{24} y$, then we have

$$
\frac{3}{11}\left|x-\frac{11 y}{24}\right|=\frac{3}{11}\left(x-\frac{11 y}{24}\right) \leq \frac{3}{11}\left(x-\frac{y}{8}\right)=\frac{3}{11} d(x, T y) .
$$

Hence, $d(T x, T y) \leq \frac{6}{11} \frac{d(x, T y)}{2} \leq \frac{6}{11} M(x, y)$. If $x<\frac{11 y}{24}$, then

$$
\frac{3}{11}\left|x-\frac{11 y}{24}\right|=\frac{3}{11}\left(\frac{11 y}{24}-x\right) \leq \frac{3(y-x)}{11}=\frac{3}{11} d(x, y) \leq \frac{6}{11} M(x, y) .
$$

Hence, $d(T x, T y) \leq \frac{6}{11} M(x, y)$. If $x, y \in M_{1}$, then

$$
d(T x, T y)=\left|\frac{3 x}{11}-\frac{3 y}{11}\right|=\frac{3}{11} d(x, y) \leq \frac{6}{11} M(x, y) .
$$

If $x, y \in M_{2}$, then $d(T x, T y)=\left|\frac{x}{8}-\frac{y}{8}\right|=\frac{1}{8} d(x, y) \leq \frac{6}{11} M(x, y)$. Define $\alpha(x, y)=1$ whenever $x, y \in M_{1} \cup M_{2}$ and $\alpha(x, y)=1$ otherwise. Also, put $\psi(t)=\frac{6 t}{11}$ for all $t \geq 0$. Then it is easy to see that $\alpha(x, y) d(T x, T y) \leq \psi(M(x, y))$ for all $x, y \in M$. Also, $\alpha(1, T 1)=\alpha(1,3 / 11) \geq 1$. If $\alpha(x, y) \geq 1$, then $x, y \in M_{1} \cup M_{2}$ and so $\alpha(T x, T y) \geq 1$. Thus, $T$ is $\alpha$-admissible. It is easy to show that if $\left\{x_{n}\right\}$ is a sequence in $M$ such that $\alpha\left(x_{n}, x_{n+1}\right) \geq 1$ for all $n$ and $x_{n} \rightarrow x$, then $\alpha\left(x_{n}, x\right) \geq 1$ for all $n$. Now, by using Theorem 1.1, $T$ has a fixed point. Now, we show that Theorem 1 in [5] does not apply here. Put $x=1$ and $y=2$. Then $d(T 1, T 2)=$ $\left|\frac{3}{11}-4\right|=\frac{41}{11}, d(1,2)=1, d(1, T 1)=d\left(1, \frac{3}{11}\right)=\frac{8}{11}, d(2, T 2)=d(2,4)=2, d(1, T 2)=d(1,4)=$ $3, d(2, T 1)=d\left(2, \frac{3}{11}\right)=\frac{19}{11}$. Thus, $N(1,2)=3$ and so $d(T 1, T 2)=\frac{41}{11}>3=N(1,2)$, where $N(x, y)=\max \{d(x, y), d(x, T x), d(y, T y), d(x, T y), d(y, T x)\}$.

\section{An affirmative answer for an open problem}

After providing some results on fixed points of quasi-contractions on normal cone metric spaces by Ilic and Rakocevic in 2009 [8], Kadelburg, Radenovic and Rakocevic generalized the results by considering an additional assumption and deleting the assumption on 
normality [9]. In 2011, Haghi, Rezapour and Shahzad proved same results without the additional assumption and for $\lambda \in(0,1)[10]$. Then Amini-Harandi proved a result on the existence of fixed points of set-valued quasi-contraction maps in metric spaces by using the technique of [10] (see [11]). But similar to [9], he could prove it only for $\lambda \in\left(0, \frac{1}{2}\right)$ [11]. In 2012, Haghi, Rezapour and Shahzad proved the main result of [11] by using a simple method [12]. Also, they introduced quasi-contraction type multifunctions and showed that the main result of [11] holds for quasi-contraction type multifunctions. They raised an open problem about the difference between quasi-contraction and quasi-contraction type multifunctions [12]. In this section, we give a positive answer to the question. Let $(X, d)$ be a metric space. Recall that the multifunction $T: X \rightarrow 2^{X}$ is called quasi-contraction whenever there exists $\lambda \in(0,1)$ such that

$$
H(T x, T y) \leq \lambda \max \{d(x, y), d(x, T x), d(y, T y), d(x, T y), d(y, T x)\}
$$

for all $x, y \in X$ [11]. Also, a multifunction $T: X \rightarrow 2^{X}$ is called quasi-contraction type whenever there exists $\lambda \in(0,1)$ such that

$$
H(T x, T y) \leq \lambda \max \{d(x, T x), d(y, T y), d(x, T y), d(y, T x)\}
$$

for all $x, y \in X$ [12]. It is clear that each quasi-contraction type multifunction is a quasicontractive multifunction. In 2012, Haghi, Rezapour and Shahzad raised this question that (see [12]): Is there any quasi-contractive multifunction which is not quasi-contraction type? By providing the following example, we give a positive answer to the problem.

Example 2.1 Let $X=[0,2]$ and $d(x, y)=|x-y|$. Define $T: X \rightarrow C B(X)$ by $T x=\left[1, \frac{5}{4}\right]$ whenever $x \in[0,3 / 4], T x=\left[\frac{7}{8}, \frac{9}{8}\right]$ whenever $x \in\left(\frac{3}{4}, \frac{5}{4}\right)$ and $T x=\left[\frac{3}{4}, 1\right]$ whenever $x \in\left[\frac{5}{4}, 2\right]$. We show that $T$ is a quasi-contraction while it is not a quasi-contractive type multifunction. Put $N(x, y)=\max \{d(x, y), d(x, T x), d(y, T y), d(x, T y), d(y, T x)\}$ for all $x, y \in X$. First, we show that $T$ is a quasi-contraction. It is easy to check that $H(T x, T y) \leq \frac{1}{2} N(x, y)$ whenever $x, y \in\left[0, \frac{3}{4}\right]$ or $x, y \in\left(\frac{3}{4}, \frac{5}{4}\right)$ or $x, y \in\left[\frac{5}{4}, 2\right]$. If $x \in\left[0, \frac{3}{4}\right]$ and $y \in\left[\frac{5}{4}, 2\right]$, then $H(T x, T y)=\frac{1}{4}$ and $d(x, y) \geq \frac{5}{4}-\frac{3}{4}=\frac{1}{2}$. Hence, $H(T x, T y)=\frac{1}{4} \leq \frac{1}{2} d(x, y) \leq \frac{1}{2} N(x, y)$. If $x \in\left[0, \frac{3}{4}\right]$ and $y \in\left(\frac{3}{4}, \frac{5}{4}\right)$, then $H(T x, T y)=\frac{1}{8}$ and $d(x, T x) \geq \frac{1}{4}$. Hence,

$$
H(T x, T y)=\frac{1}{8} \leq \frac{1}{2} d(x, T x) \leq \frac{1}{2} N(x, y) .
$$

If $x \in\left[\frac{5}{4}, 2\right]$ and $y \in\left(\frac{3}{4}, \frac{5}{4}\right)$, then $H(T x, T y)=H\left(\left[\frac{3}{4}, 1\right],\left[\frac{7}{8}, \frac{9}{8}\right]\right)=\frac{1}{8}$ and $d(x, T x) \geq \frac{1}{4}$. Hence, $H(T x, T y)=\frac{1}{8} \leq \frac{1}{2} d(x, T x) \leq \frac{1}{2} N(x, y)$. Therefore, $T$ is a quasi-contraction with $\lambda=\frac{1}{2}$. Now, put $x=\frac{3}{4}$ and $y=\frac{5}{4}$. Then we have $d\left(\frac{3}{4}, T \frac{3}{4}\right)=d\left(\frac{3}{4},\left[1, \frac{5}{4}\right]\right)=\frac{1}{4}, d\left(\frac{5}{4}, T \frac{5}{4}\right)=d\left(\frac{5}{4},\left[\frac{3}{4}, 1\right]\right)=$ $\frac{1}{4}, d\left(\frac{3}{4}, T \frac{5}{4}\right)=d\left(\frac{3}{4},\left[\frac{3}{4}, 1\right]\right)=0$ and $d\left(\frac{5}{4}, T \frac{3}{4}\right)=d\left(\frac{5}{4},\left[1, \frac{5}{4}\right]\right)=0$. Hence, $N_{1}\left(\frac{3}{4}, \frac{5}{4}\right)=\max \left\{d\left(\frac{3}{4}\right.\right.$, $\left.\left.T \frac{3}{4}\right), d\left(\frac{5}{4}, T \frac{5}{4}\right), d\left(\frac{3}{4}, T \frac{5}{4}\right), d\left(\frac{5}{4}, T \frac{3}{4}\right)\right\}=\max \left\{\frac{1}{4}, 0\right\}=\frac{1}{4}$. Also, we have $H\left(T \frac{3}{4}, T \frac{5}{4}\right)=H\left(\left[1, \frac{5}{4}\right]\right.$, $\left.\left[\frac{3}{4}, 1\right]\right)=\frac{1}{4}$. Thus, $H\left(T \frac{3}{4}, T \frac{5}{4}\right)>\lambda N_{1}\left(\frac{3}{4}, \frac{5}{4}\right)$ for all $\lambda \in(0,1)$. This shows that $T$ is not a quasicontractive type multifunction.

\section{Main results}

Now, we are ready to state and prove our main results. Let $(X, d)$ be a metric space, $\alpha: X \times X \rightarrow[0, \infty)$ be a mapping and $T: X \rightarrow C B(X)$ be a multifunction. We say that $X$ satisfies the condition $\left(C_{\alpha}\right)$ whenever for each sequence $\left\{x_{n}\right\}$ in $X$ with $\alpha\left(x_{n}, x_{n+1}\right) \geq 1$ for all $n$ 
and $x_{n} \rightarrow x$, there exists a subsequence $\left\{x_{n_{k}}\right\}$ of $\left\{x_{n}\right\}$ such that $\alpha\left(x_{n_{k}}, x\right) \geq 1$ for all $k$ (see [13] for the idea of this notion). Recall that $T$ is continuous whenever $H\left(T x_{n}, T x\right) \rightarrow 0$ for all sequence $\left\{x_{n}\right\}$ in $X$ with $x_{n} \rightarrow x$. Also, we say that $T$ is $\alpha$-admissible whenever for each $x \in X$ and $y \in T x$ with $\alpha(x, y) \geq 1$, we have $\alpha(y, z) \geq 1$ for all $z \in T y$. Note that this notion is different from the notion of $\alpha_{*}$-admissible multifunctions which has been provided in [7]. But, by providing a similar proof to that of Theorem $2.1 \mathrm{in}$ [7], we can prove the following result.

Theorem 3.1 Let $(X, d)$ be a complete metric space, $\alpha: X \times X \rightarrow[0, \infty)$ be a function, $\psi \in$ $\Psi$ be a strictly increasing map and $T: X \rightarrow C B(X)$ be an $\alpha$-admissible multifunction such that $\alpha(x, y) H(T x, T y) \leq \psi(d(x, y))$ for all $x, y \in X$ and there exist $x_{0} \in X$ and $x_{1} \in T x_{0}$ with $\alpha\left(x_{0}, x_{1}\right) \geq 1$. If $T$ is continuous or $X$ satisfies the condition $\left(C_{\alpha}\right)$, then $T$ has a fixed point.

Corollary 3.2 Let $(X, d)$ be a complete metric space, $\psi \in \Psi$ be a strictly increasing map, $x^{*} \in X$ and $T: X \rightarrow C B(X)$ be a multifunction such that $H(T x, T y) \leq \psi(d(x, y))$ for all $x, y \in$ $X$ with $x^{*} \in T x \cap T y$. Suppose that there exist $x_{0} \in X$ and $x_{1} \in T x_{0}$ such that $x^{*} \in T x_{0} \cap T x_{1}$. Assume that for each $x \in X$ and $y \in T x$ with $x^{*} \in T x \cap T y$, we have $x^{*} \in T y \cap T z$ for all $z \in T y$. If $T$ is continuous or $X$ satisfies the condition $\left(C_{\alpha}\right)$, then $T$ has a fixed point.

Proof Define $\alpha: X \times X \rightarrow[0,+\infty)$ by $\alpha(x, y)=1$ whenever $x^{*} \in T x \cap T y$ and $\alpha(x, y)=0$ otherwise. Then, by using Theorem 3.1, $T$ has a fixed point.

Let $(X, \preceq)$ be an ordered set and $A, B \subseteq X$. We say that $A \preceq B$ whenever for each $a \in A$ there exists $b \in B$ such that $a \preceq b$.

Corollary 3.3 Let $(X, \preceq, d)$ be a complete ordered metric space, $\psi \in \Psi$ be a strictly increasing map and $T: X \rightarrow C B(X)$ be a multifunction such that $H(T x, T y) \leq \psi(d(x, y))$ for all $x, y \in X$ with $T x \preceq T y$ or $T y \preceq T x$. Suppose that there exist $x_{0} \in X$ and $x_{1} \in T x_{0}$ such that $T x_{0} \preceq T x_{1}$ or $T x_{1} \preceq T x_{0}$. Assume that for each $x \in X$ and $y \in T x$ with $T x \preceq T y$ or $T y \preceq T x$, we have $T y \preceq T z$ or $T z \preceq T y$ for all $z \in T y$. If $T$ is continuous or $X$ satisfies the condition $\left(C_{\alpha}\right)$, then $T$ has a fixed point.

Now, we give the following result.

Theorem 3.4 Let $(X, d)$ be a complete metric space, $\alpha: X \times X \rightarrow[0, \infty)$ be a function, $\psi \in \Psi$ be a strictly increasing map and $T: X \rightarrow C B(X)$ be an $\alpha$-admissible $\alpha$ - $\psi$-Ciric generalized multifunction, and let there exist $x_{0} \in X$ and $x_{1} \in T x_{0}$ with $\alpha\left(x_{0}, x_{1}\right) \geq 1$. If $T$ is continuous, then $T$ has a fixed point.

Proof If $x_{1}=x_{0}$, then we have nothing to prove. Let $x_{1} \neq x_{0}$. Then we have

$$
\begin{aligned}
d\left(x_{1}, T x_{1}\right) & \leq \alpha\left(x_{0}, x_{1}\right) H\left(T x_{0}, T x_{1}\right) \\
& \leq \psi\left(\max \left\{d\left(x_{0}, x_{1}\right), d\left(x_{0}, T x_{0}\right), d\left(x_{1}, T x_{1}\right), \frac{d\left(x_{0}, T x_{1}\right)+d\left(x_{1}, T x_{0}\right)}{2}\right\}\right) \\
& =\psi\left(\max \left\{d\left(x_{0}, x_{1}\right), d\left(x_{1}, T x_{1}\right), \frac{d\left(x_{0}, T x_{1}\right)}{2}\right\}\right) \\
& \leq \psi\left(\max \left\{d\left(x_{0}, x_{1}\right), d\left(x_{1}, T x_{1}\right), \frac{d\left(x_{0}, x_{1}\right)+d\left(x_{1}, T x_{1}\right)}{2}\right\}\right) \\
& =\psi\left(\max \left\{d\left(x_{0}, x_{1}\right), d\left(x_{1}, T x_{1}\right)\right\}\right) .
\end{aligned}
$$


If $\max \left\{d\left(x_{0}, x_{1}\right), d\left(x_{1}, T x_{1}\right)\right\}=d\left(x_{1}, T x_{1}\right)$, then $d\left(x_{1}, T x_{1}\right) \leq \psi\left(d\left(x_{1}, T x_{1}\right)\right)$ and so we get $d\left(x_{1}, T x_{1}\right)=0$. Thus, $d\left(x_{0}, x_{1}\right)=0$, which is a contradiction. Hence, we obtain $\max \left\{d\left(x_{0}, x_{1}\right)\right.$, $\left.d\left(x_{1}, T x_{1}\right)\right\}=d\left(x_{0}, x_{1}\right)$ and so $d\left(x_{1}, T x_{1}\right) \leq \psi\left(d\left(x_{0}, x_{1}\right)\right)$. If $x_{1} \in T x_{1}$, then $x_{1}$ is a fixed point of $T$. Let $x_{1} \notin T x_{1}$ and $q>1$. Then

$$
0<d\left(x_{1}, T x_{1}\right)<q \psi\left(d\left(x_{0}, x_{1}\right)\right) .
$$

Put $t_{0}=d\left(x_{0}, x_{1}\right)$. Then $t_{0}>0$ and $d\left(x_{1}, T x_{1}\right)<q \psi\left(t_{0}\right)$. Hence, there exists $x_{2} \in T x_{1}$ such that $d\left(x_{1}, x_{2}\right)<q \psi\left(t_{0}\right)$ and so $\psi\left(d\left(x_{1}, x_{2}\right)\right)<\psi\left(q \psi\left(t_{0}\right)\right)$. It is clear that $x_{2} \neq x_{1}$. Put $q_{1}=\frac{\psi\left(q \psi\left(t_{0}\right)\right)}{\psi\left(d\left(x_{1}, x_{2}\right)\right)}$. Then $q_{1}>1$ and we have

$$
\begin{aligned}
d\left(x_{2}, T x_{2}\right) & \leq \alpha\left(x_{1}, x_{2}\right) H\left(T x_{1}, T x_{2}\right) \\
& \leq \psi\left(\max \left\{d\left(x_{1}, x_{2}\right), d\left(x_{1}, T x_{1}\right), d\left(x_{2}, T x_{2}\right), \frac{d\left(x_{1}, T x_{2}\right)+d\left(x_{2}, T x_{1}\right)}{2}\right\}\right) \\
& =\psi\left(\max \left\{d\left(x_{1}, x_{2}\right), d\left(x_{2}, T x_{2}\right), \frac{d\left(x_{1}, T x_{2}\right)}{2}\right\}\right) \\
& \leq \psi\left(\max \left\{d\left(x_{1}, x_{2}\right), d\left(x_{2}, T x_{2}\right)\right\}\right) .
\end{aligned}
$$

Similarly, we should have $\max \left\{d\left(x_{1}, x_{2}\right), d\left(x_{2}, T x_{2}\right)\right\}=d\left(x_{2}, x_{2}\right)$ and so we get

$$
d\left(x_{2}, T x_{2}\right) \leq \psi\left(d\left(x_{1}, x_{2}\right)\right) .
$$

If $x_{2} \in T x_{2}$, then $x_{2}$ is a fixed point of $T$. Let $x_{2} \notin T x_{2}$. Then $0<d\left(x_{2}, T x_{2}\right)<q_{1} \psi\left(d\left(x_{1}, x_{2}\right)\right)$. Hence, there exists $x_{3} \in T x_{2}$ such that $d\left(x_{2}, x_{3}\right)<q_{1} \psi\left(d\left(x_{1}, x_{2}\right)\right)=\psi\left(q \psi\left(t_{0}\right)\right)$. It is clear that $x_{3} \neq x_{2}$ and $\psi\left(d\left(x_{2}, x_{3}\right)\right)<\psi^{2}\left(q \psi\left(t_{0}\right)\right)$. Put $q_{2}=\frac{\psi^{2}\left(q \psi\left(t_{0}\right)\right)}{\psi\left(d\left(x_{2}, x_{3}\right)\right)}$. Then $q_{2}>1$. Also, we have

$$
\begin{aligned}
d\left(x_{3}, T x_{3}\right) & \leq \alpha\left(x_{2}, x_{3}\right) H\left(T x_{2}, T x_{3}\right) \\
& \leq \psi\left(\max \left\{d\left(x_{2}, x_{3}\right), d\left(x_{2}, T x_{2}\right), d\left(x_{3}, T x_{3}\right), \frac{d\left(x_{2}, T x_{3}\right)+d\left(x_{3}, T x_{2}\right)}{2}\right\}\right) \\
& =\psi\left(\max \left\{d\left(x_{2}, x_{3}\right), d\left(x_{3}, T x_{3}\right), \frac{d\left(x_{2}, T x_{3}\right)}{2}\right\}\right) \\
& \leq \psi\left(\max \left\{d\left(x_{2}, x_{3}\right), d\left(x_{3}, T x_{3}\right)\right\}\right) .
\end{aligned}
$$

By continuing this process, we obtain a sequence $\left\{x_{n}\right\}$ in $X$ such that $x_{n} \in T x_{n-1}, x_{n} \neq x_{n-1}$ and $d\left(x_{n}, x_{n+1}\right) \leq \psi^{n-1}\left(q \psi\left(t_{0}\right)\right)$ for all $n$. Let $m>n$. Then

$$
d\left(x_{n}, x_{m}\right) \leq \sum_{i=n}^{m-1} d\left(x_{i}, x_{i+1}\right) \leq \sum_{i=n}^{m-1} \psi^{i-1}\left(q \psi\left(t_{0}\right)\right)
$$

and so $\left\{x_{n}\right\}$ is a Cauchy sequence in $X$. Hence, there exists $x^{\star} \in X$ such that $x_{n} \rightarrow x^{\star}$. If $T$ is continuous, then

$$
d\left(x^{\star}, T x^{\star}\right)=\lim _{n \rightarrow \infty} d\left(x_{n+1}, T x^{\star}\right) \leq \lim _{n \rightarrow \infty} H\left(T x_{n}, T x^{\star}\right)=0
$$

and so $x^{\star} \in T x^{\star}$. 
Corollary 3.5 Let $(X, d)$ be a complete metric space, $\psi \in \Psi$ be a strictly increasing map, $x^{*} \in X$ and $T: X \rightarrow C B(X)$ be a multifunction such that

$$
H(T x, T y) \leq \psi\left(\max \left\{d(x, y), d(x, T x), d(y, T y), \frac{d(x, T y)+d(y, T x)}{2}\right\}\right)
$$

for all $x, y \in X$ with $x^{*} \in T x \cap T y$. Suppose that there exist $x_{0} \in X$ and $x_{1} \in T x_{0}$ such that $x^{*} \in T x_{0} \cap T x_{1}$. Assume that for each $x \in X$ and $y \in T x$ with $x_{0} \in T x \cap T y$, we have $x_{0} \in$ $T y \cap T z$ for all $z \in T y$. If $T$ is continuous, then $T$ has a fixed point.

Corollary 3.6 Let $(X, \preceq, d)$ be a complete ordered metric space, $\psi \in \Psi$ be a strictly increasing map and $T: X \rightarrow C B(X)$ be a multifunction such that

$$
H(T x, T y) \leq \psi\left(\max \left\{d(x, y), d(x, T x), d(y, T y), \frac{d(x, T y)+d(y, T x)}{2}\right\}\right)
$$

for all $x, y \in X$ with $T x \preceq T y$ or $T y \preceq T x$. Suppose that there exist $x_{0} \in X$ and $x_{1} \in T x_{0}$ such that $T x_{0} \preceq T x_{1}$ or $T x_{1} \preceq T x_{0}$. Assume that for each $x \in X$ and $y \in T x$ with $T x \preceq T y$ or $T y \preceq$ $T x$, we have $T y \preceq T z$ or $T z \preceq T y$ for all $z \in T y$. If $T$ is continuous, then $T$ has a fixed point.

Now, we give the following result about a fixed point of self-maps on complete metric spaces.

Theorem 3.7 Let $(X, d)$ be a complete metric space, $\alpha: X \times X \rightarrow[0, \infty)$ be a mapping, $\phi:[0, \infty) \rightarrow[0, \infty)$ be a continuous and nondecreasing map such that $\phi(t)<t$ for all $t>0$ and $T$ be a self-map on $X$ such that

$$
\alpha(x, y) d(T x, T y) \leq \phi\left(\max \left\{d(x, y), d(x, T x), d(y, T y), \frac{d(x, T y)+d(y, T x)}{2}\right\}\right)
$$

for all $x, y \in X$. Assume that there exists $x_{0} \in X$ such that $\alpha\left(T^{i} x_{0}, T^{j} x_{0}\right) \geq 1$ for all $i, j \geq 0$ with $i \neq j$. Suppose that $T$ is continuous or $\alpha\left(T^{i} x_{0}, x\right) \geq 1$ for all $i \geq 0$ whenever $T^{i} x_{0} \rightarrow x$. Then $T$ has a fixed point.

Proof It is easy to check that $\lim _{n \rightarrow \infty} \phi^{n}(t)=0$ for all $t>0$. Let $x_{n}=T x_{n-1}$ for all $n \geq 1$. If $x_{n}=x_{n-1}$ for some $n$, then $x_{n-1}$ is a fixed point of $T$. Suppose that $x_{n} \neq x_{n-1}$ for all $n$. Then we have

$$
\begin{aligned}
d\left(x_{n+1}, x_{n}\right)= & d\left(T x_{n}, T x_{n-1}\right) \leq \alpha\left(x_{n}, x_{n-1}\right) d\left(T x_{n}, T x_{n-1}\right) \\
\leq & \phi\left(\operatorname { m a x } \left\{d\left(x_{n}, x_{n-1}\right), d\left(x_{n}, T x_{n}\right), d\left(x_{n-1}, T x_{n-1}\right),\right.\right. \\
& \left.\left.\frac{d\left(x_{n-1}, T x_{n}\right)+d\left(x_{n}, T x_{n-1}\right)}{2}\right\}\right) \\
= & \phi\left(\max \left\{d\left(x_{n-1}, x_{n}\right), d\left(x_{n}, x_{n+1}\right), \frac{d\left(x_{n-1}, x_{n+1}\right)}{2}\right\}\right) \\
\leq & \phi\left(\max \left\{d\left(x_{n-1}, x_{n}\right), d\left(x_{n}, x_{n+1}\right), \frac{d\left(x_{n-1}, x_{n}\right)+d\left(x_{n}, x_{n+1}\right)}{2}\right\}\right) \\
= & \phi\left(\max \left\{d\left(x_{n-1}, x_{n}\right), d\left(x_{n}, x_{n+1}\right)\right\}\right) .
\end{aligned}
$$


Since $d\left(x_{n+1}, x_{n}\right) \leq \phi\left(d\left(x_{n+1}, x_{n}\right)\right)$ does not hold, we get $d\left(x_{n+1}, x_{n}\right) \leq \phi\left(d\left(x_{n}, x_{n-1}\right)\right)$. Since $\phi$ is nondecreasing, we have

$$
d\left(x_{n+1}, x_{n}\right) \leq \phi\left(d\left(x_{n}, x_{n-1}\right)\right) \leq \phi^{2}\left(d\left(x_{n-1}, x_{n-2}\right)\right) \leq \cdots \leq \phi^{n}\left(d\left(x_{1}, x_{0}\right)\right)
$$

for all $n$. Hence, $d\left(x_{n+1}, x_{n}\right) \rightarrow 0$. If $\left\{x_{n}\right\}$ is not a Cauchy sequence, then there exists $\varepsilon>0$ and subsequences $\left\{x_{n_{i}}\right\}$ and $\left\{x_{m_{i}}\right\}$ of $\left\{x_{n}\right\}$ with $n_{i}<m_{i}$ such that $d\left(x_{n_{i}}, x_{m_{i}}\right)>\varepsilon$ for all $i$. For each $n_{i}$, put $k_{i}=\min \left\{m_{i} \mid d\left(x_{n_{i}}, x_{m_{i}}\right)>\varepsilon\right\}$. Then we have

$$
\varepsilon<d\left(x_{n_{i}}, x_{k_{i}}\right) \leq d\left(x_{n_{i}}, x_{k_{i}-1}\right)+d\left(x_{k_{i}-1}, x_{k_{i}}\right) \leq \varepsilon+d\left(x_{k_{i}-1}, x_{k_{i}}\right)
$$

and so $d\left(x_{n_{i}}, x_{k_{i}}\right) \rightarrow \varepsilon$. But we have

$$
\begin{aligned}
& d\left(x_{n_{i}}, x_{k_{i}}\right)-d\left(x_{n_{i}}, x_{n_{i}+1}\right)-d\left(x_{k_{i}}, x_{k_{i}+1}\right) \\
& \quad \leq d\left(x_{n_{i}+1}, x_{k_{i}+1}\right) \leq d\left(x_{n_{i}}, x_{k_{i}}\right)+d\left(x_{n_{i}}, x_{n_{i}+1}\right)+d\left(x_{k_{i}}, x_{k_{i}+1}\right)
\end{aligned}
$$

and so $d\left(x_{n_{i}+1}, x_{k_{i}+1}\right) \rightarrow \varepsilon$. Thus, we get

$$
\begin{aligned}
\max & \left\{d\left(x_{n_{i}}, x_{k_{i}}\right), d\left(x_{n_{i}+1}, x_{n_{i}}\right), d\left(x_{k_{i}+1}, x_{k_{i}}\right), \frac{1}{2}\left[d\left(x_{n_{i}+1}, x_{k_{i}}\right)+d\left(x_{k_{i}+1}, x_{n_{i}}\right)\right]\right\} \\
\leq & \max \left\{d\left(x_{n_{i}}, x_{k_{i}}\right), d\left(x_{n_{i}+1}, x_{n_{i}}\right), d\left(x_{k_{i}+1}, x_{k_{i}}\right),\right. \\
& \left.\frac{1}{2}\left[d\left(x_{n_{i}+1}, x_{k_{i}+1}\right)+d\left(x_{k_{i}+1}, x_{k_{i}}\right)+d\left(x_{k_{i}+1}, x_{k_{i}}\right)+d\left(x_{k_{i}}, x_{n_{i}}\right)\right]\right\} \\
\leq & \max \left\{d\left(x_{n_{i}}, x_{k_{i}}\right), d\left(x_{n_{i}+1}, x_{n_{i}}\right), d\left(x_{k_{i}+1}, x_{k_{i}}\right),\right. \\
& \left.\frac{1}{2}\left[2 d\left(x_{n_{i}}, x_{k_{i}}\right)+3 d\left(x_{k_{i}+1}, x_{k_{i}}\right)+d\left(x_{n_{i}+1}, x_{n_{i}}\right)\right]\right\} \\
\leq & d\left(x_{n_{i}}, x_{k_{i}}\right)+\frac{3}{2} d\left(x_{k_{i}+1}, x_{k_{i}}\right)+d\left(x_{n_{i}+1}, x_{n_{i}}\right)
\end{aligned}
$$

and so $M\left(x_{n_{i}}, x_{k_{i}}\right) \rightarrow \varepsilon$. On the other hand, we have

$$
d\left(x_{n_{i}+1}, x_{k_{i}+1}\right)=d\left(T x_{n_{i}}, T x_{k_{i}}\right) \leq \alpha\left(x_{n_{i}}, x_{k_{i}}\right) d\left(T x_{n_{i}}, T x_{k_{i}}\right) \leq \phi\left(M\left(x_{n_{i}}, x_{k_{i}}\right)\right)
$$

and so $\varepsilon \leq \phi(\varepsilon)$. This contradiction shows that $\left\{x_{n}\right\}$ is a Cauchy sequence. Since $X$ is complete, there exists $x \in X$ such that $x_{n} \rightarrow x$. If $T$ is continuous, then we get

$$
d(x, T x)=\lim _{n \rightarrow \infty} d\left(x_{n+1}, T x\right)=\lim _{n \rightarrow \infty} d\left(T x_{n}, T x\right)=0 .
$$

Now, suppose that $\alpha\left(T^{i} x_{0}, x\right) \geq 1$ for all $i \geq 0$ whenever $T^{i} x_{0} \rightarrow x$. Then

$$
\begin{aligned}
d(x, T x) & =\lim _{n \rightarrow \infty} d\left(x_{n+1}, T x\right)=\lim _{n \rightarrow \infty} d\left(T x_{n}, T x\right) \leq \lim _{n \rightarrow \infty} \alpha\left(x_{n}, x\right) d\left(T x_{n}, T x\right) \\
& \leq \lim _{n \rightarrow \infty} \phi\left(\max \left\{d\left(x_{n}, x\right), d\left(x_{n}, x_{n+1}\right), d(x, T x),\left(d\left(x_{n}, T x\right)+d\left(x, x_{n+1}\right)\right) / 2\right\}\right) \\
& =\phi(d(x, T x)) .
\end{aligned}
$$

Thus, $d(x, T x)=0$. 
Here, we give the following example to show that there are discontinuous mappings satisfying the conditions of Theorem 3.7.

Example 3.1 Let $X=[0, \infty)$ and $d(x, y)=|x-y|$. Define $T: X \rightarrow X$ by $T x=x+2$ whenever $x \in[0,1], T x=\frac{3}{2}$ whenever $x \in(1,2)$ and $T x=x^{3}+2 x+1$ whenever $x \in[2, \infty)$. Also, define the mappings $\phi:[0, \infty) \rightarrow[0, \infty)$ and $\alpha: X \times X \rightarrow[0, \infty)$ by $\phi(t)=\frac{t}{2}, \alpha(x, y)=1$ whenever $x, y \in(1,2)$ and $\alpha(x, y)=0$ otherwise. An easy calculation shows us that

$$
\alpha(x, y) d(T x, T y) \leq \phi\left(\max \left\{d(x, y), d(x, T x), d(y, T y), \frac{d(x, T y)+d(y, T x)}{2}\right\}\right)
$$

for all $x, y \in X$. Put $x_{0}=\frac{3}{2}$. Since $T^{i} x_{0}=x_{0}$ for all $i \geq 1, \alpha\left(T^{i} x_{0}, T^{j} x_{0}\right) \geq 1$ for all $i, j \geq 0$ with $i \neq j$ and $\alpha\left(T^{i} x_{0}, x\right) \geq 1$ for all $i \geq 0$ whenever $T^{i} x_{0} \rightarrow x$. Thus, the map $T$ satisfies the conditions of Theorem 3.7. Note that $x_{0}=\frac{3}{2}$ is a fixed point of $T$.

Corollary 3.8 Let $(X, \preceq, d)$ be a complete ordered metric space, $\phi:[0, \infty) \rightarrow[0, \infty)$ be a continuous and nondecreasing map such that $\phi(t)<t$ for all $t>0$ and $T$ be a self-map on $X$ such that

$$
d(T x, T y) \leq \phi\left(\max \left\{d(x, y), d(x, T x), d(y, T y), \frac{d(x, T y)+d(y, T x)}{2}\right\}\right)
$$

for all comparable elements $x, y \in X$. Assume that there exists $x_{0} \in X$ such that $T^{i} x_{0}$ and $T^{j} x_{0}$ are comparable for all $i, j \geq 0$ with $i \neq j$. Suppose that $T$ is continuous or $T^{i} x_{0}$ and $x$ are comparable for all $i \geq 0$ whenever $T^{i} x_{0} \rightarrow x$. Then $T$ has a fixed point.

Proof Define the mapping $\alpha: X \times X \rightarrow[0,+\infty)$ by $\alpha(x, y)=1$ whenever $x$ and $y$ are comparable and $\alpha(x, y)=0$ otherwise. Then, by using Theorem 3.7, $T$ has a fixed point.

Corollary 3.9 Let $(X, \preceq, d)$ be a complete ordered metric space, $z \in X, \phi:[0, \infty) \rightarrow[0, \infty)$ be a continuous and nondecreasing map such that $\phi(t)<t$ for all $t>0$ and $T$ be a self-map on $X$ such that

$$
d(T x, T y) \leq \phi\left(\max \left\{d(x, y), d(x, T x), d(y, T y), \frac{d(x, T y)+d(y, T x)}{2}\right\}\right)
$$

for all $x, y \in X$ which are comparable with $z$. Assume that there exists $x_{0} \in X$ such that $T^{i} x_{0}$ and $T^{j} x_{0}$ are comparable with $z$ for all $i, j \geq 0$ with $i \neq j$. Suppose that $T$ is continuous or $T^{i} x_{0}$ and $x$ are comparable with $z$ for all $i \geq 0$ whenever $T^{i} x_{0} \rightarrow x$. Then $T$ has a fixed point.

Proof Define the mapping $\alpha: X \times X \rightarrow[0,+\infty)$ by $\alpha(x, y)=1$ whenever $x$ and $y$ are comparable with $z$ and $\alpha(x, y)=0$ otherwise. Then, by using Theorem 3.7, $T$ has a fixed point.

Finally, by using [14], we can find also some equivalent conditions for some presented results. We give two following results in this way. This shows us the importance of the main results of [14]. Also, Example 3.1 leads us to the fact that there are discontinuous mappings satisfying the conditions of the following results. 
Proposition 3.10 Let $(X, d)$ be a complete metric space, $\alpha: X \times X \rightarrow[0, \infty)$ be a mapping, $\psi:[0, \infty) \rightarrow[0, \infty)$ be a lower semi-continuous function, $\eta:[0, \infty) \rightarrow[0, \infty)$ be a map such that $\eta^{-1}(\{0\})=\{0\}$ and $\liminf _{t \rightarrow \infty} \eta(t)>0$ for all $t>0$ and $T$ be a self-map on $X$ such that

$$
\psi(\alpha(x, y) d(T x, T y)) \leq \psi(M(x, y))-\eta(M(x, y))
$$

for all $x, y \in X$. Assume that there exists $x_{0} \in X$ such that $\alpha\left(T^{i} x_{0}, T^{j} x_{0}\right) \geq 1$ for all $i, j \geq 0$ with $i \neq j$. Suppose that $T$ is continuous or $\alpha\left(T^{i} x_{0}, x\right) \geq 1$ for all $i \geq 0$ whenever $T^{i} x_{0} \rightarrow x$. Then $T$ has a fixed point.

Proposition 3.11 Let $(X, d)$ be a complete metric space, $\alpha: X \times X \rightarrow[0, \infty)$ be a mapping, $\psi \in \Psi$ be a nondecreasing map which is continuous from right at each point, $\phi$ : $[0, \infty) \rightarrow[0, \infty)$ be a map such that $\phi(t)<t$ for all $t>0$ and $T$ be a self-map on $X$ such that $\psi(\alpha(x, y) d(T x, T y)) \leq \phi(\psi(M(x, y)))$ for all $x, y \in X$. Assume that there exists $x_{0} \in X$ such that $\alpha\left(T^{i} x_{0}, T^{j} x_{0}\right) \geq 1$ for all $i, j \geq 0$ with $i \neq j$. Suppose that $T$ is continuous or $\alpha\left(T^{i} x_{0}, x\right) \geq 1$ for all $i \geq 0$ whenever $T^{i} x_{0} \rightarrow x$. Then $T$ has a fixed point.

\section{Competing interests}

The authors declare that they have no competing interests.

\section{Authors' contributions}

All authors contributed equally and significantly in writing this paper. All authors read and approved the final manuscript.

\section{Author details}

${ }^{1}$ Department of Mathematics, Science and Research Branch, Islamic Azad University, Tehran, Iran. ${ }^{2}$ Department of Mathematics, Azarbaijan Shahid Madani University, Tabriz, Azarshahr, Iran. ${ }^{3}$ Department of Mathematics, King Abdulaziz University, P.O. Box 80203, Jeddah, 21859, Saudi Arabia.

\section{Acknowledgements}

The authors express their gratitude to the referees for their helpful suggestions concerning the final version of this paper.

Received: 26 July 2012 Accepted: 13 January 2013 Published: 6 February 2013

\section{References}

1. Samet, B, Vetro, C, Vetro, P: Fixed point theorems for $\alpha$ - $\psi$-contractive type mappings. Nonlinear Anal. 75, 2154-2165 (2012)

2. Alikhani, H, Rezapour, S, Shahzad, N: Fixed points of a new type contractive mappings and multifunctions. Filomat (2013, to appear)

3. Ciric, LB: Fixed points for generalized multivalued mappings. Mat. Vesn. 9(24), 265-272 (1972)

4. Haghi, RH, Rezapour, S, Shahzad, N: Some fixed point generalizations are not real generalizations. Nonlinear Anal. 74, 1799-1803 (2011)

5. Ciric, LB: A generalization of Banach contraction principle. Proc. Am. Math. Soc. 45, 267-273 (1974)

6. Ciric, LB: Generalized contractions and fixed point theorems. Publ. Inst. Math. (Belgr.) 12(26), $19-26$ (1971)

7. Asl, JH, Rezapour, S, Shahzad, N: On fixed points of $\alpha-\psi$-contractive multifunctions. Fixed Point Theory Appl. 2012, 212 (2012). doi:10.1186/1687-1812-2012-212

8. Ilic, D, Rakocevic, V: Quasi-contraction on a cone metric space. Appl. Math. Lett. 22, 728-731 (2009)

9. Kadelburg, Z, Radenovic, S, Rakocevic, V: Remarks on "quasi-contraction on a cone metric space". Appl. Math. Lett. 22, 1674-1679 (2009)

10. Rezapour, S, Haghi, RH, Shahzad, N: Some notes on fixed points of quasi-contraction maps. Appl. Math. Lett. 23, 498-502 (2010)

11. Amini-Harandi, A: Fixed point theory for set-valued quasi-contraction maps in metric spaces. Appl. Math. Lett. 24, 1791-1794 (2011)

12. Haghi, RH, Rezapour, S, Shahzad, N: On fixed points of quasi-contraction type multifunctions. Appl. Math. Lett. 25 843-846 (2012)

13. Aleomraninejad, SMA, Rezapour, S, Shahzad, N: Some fixed point results on a metric space with a graph. Topol. Appl. $159,659-663$ (2012)

14. Jachymski, J: Equivalent conditions for generalized contractions on (ordered) metric spaces. Nonlinear Anal. 74, 768-774 (2011) 
doi:10.1186/1687-1812-2013-24

Cite this article as: Mohammadi et al.: Some results on fixed points of $\alpha-\psi$-Ciric generalized multifunctions. Fixed Point Theory and Applications 2013 2013:24.

Submit your manuscript to a SpringerOpen ${ }^{\circ}$ journal and benefit from:

- Convenient online submission

- Rigorous peer review

- Immediate publication on acceptance

Open access: articles freely available online

- High visibility within the field

- Retaining the copyright to your article

Submit your next manuscript at $\gg$ springeropen.com 